\title{
ANALISIS PENENTUAN SEKTOR UNGGULAN DAN STRUKTUR EKONOMI WILAYAH KABUPATEN PADANGPARIAMAN PROVINSI SUMATERA BARAT
}

\author{
Oleh \\ Arina Romarina \\ Institut Pemerintahan Dalam Negeri (IPDN) Kampus Sumatera Barat \\ arina.mep36@gmail.com
}

\begin{abstract}
$T$ The aim of the research is to identify the leading sector and the structure of economic of Padangpariaman Recency by using various analytical tools; the Klassen Typology, a combination Location Quotient dan Dynamic Location Quotient, Shift Share dan Overlay analysis. The data taken from BPS as time series data of PDRB Padangpariaman Regency ADHK 2010 in the period 2011-2016. Based on Typology Klassen analysis the mining sector and the manufacturing industries are the superior or leading sectors in Padangpariaman Regency. The DLQ analysis finds eight sectors are repositioning from non-base to be basis sectors in the future. The sectors are agriculture, forestry and fisheries sector, sector of electricity and gas procurement, trade and retail sector, information and communication sector, sector of financial services and insurance, sector of corporate services, government administration, defense and social security services, and the sector of health and social activities. The overlay analysis conclude that the sector of manufacturing industry is the main or best leading sector in Padangpariaman Regency.
\end{abstract}

Keywords: leading sector, Klassen typology, LQ, DLQ, shift share, and overlay

\section{AbSTRAK}

Denelitian ini bertujuan untuk mengidentifikasi sektor unggulan dan struktur ekonomi wilayah Kabupaten Padangpariaman dengan menggunakan berbagai alat analisis yaitu Typology Klassen, gabungan Location Quotient dan Dynamic Location Quotient, Shift Share dan Overlay. Data berasal dari Badan Pusat Statistik dalam bentuk data time series PDRB Kabupaten Padangpariaman ADHK 2010 kurun waktu tahun 2011-2016. Berdasarkan analisis Tipology Klassen, sektor Pertambangan dan Penggalian dan sektor industri pengolahan merupakan sektor prima/andalan di Kabupaten Padangpariaman. Analisis DLQ menemukan delapan sektor yang mengalami reposisi dari sektor nonbasis menjadi sektor basis di masa yang akan datang yaitu sektor pertanian, kehutanan, dan perikanan, sektor pengadaan listrik dan gas, sektor perdagangan besar dan eceran, sektor informasi dan komunikasi, sektor jasa keuangan dan asuransi, sektor jasa perusahaan, sektor administrasi pemerintahan, pertahanan dan jaminan sosial wajib dan sektor jasa kesehatan dan kegiatan sosial. Berdasarkan hitungan gabungan seluruh alat analisis (overlay), sektor industri pengolahan merupakan sektor andalan/unggulan utama di Kabupaten Padangpariaman.

Kata kunci: sektor unggulan, tipologi Klassen, $L Q, D L Q$, shift share, overlay 


\section{PENDAHULUAN}

$\mathrm{P}$ embangunan ekonomi daerah mempunyai tujuan utama yaitu meningkatkan jumlah dan jenis peluang kerja untuk masyarakat lokal, dalam upaya untuk mencapai tujuan tersebut, pemerintah daerah dan masyarakatnya harus secara bersamasama mengambil inisiatif membangun daerahnya. Oleh karena itu, pemerintah daerah harus berupaya menggunakan sumber daya yang ada di daerah tersebut dengan sebagaimana mestinya untuk kemakmuran rakyat banyak dan mendorong perekonomian untuk maju. Salah satu indikator peningkatan pembangunan bisa dinilai dari tingkat pertumbuhan ekonomi. Nilai tersebut juga merupakan salah satu faktor penting untuk mengukur keberhasilan pembangunan suatu daerah.

Pertumbuhan ekonomi merupakan laju pertumbuhan yang dibentuk dari berbagai macam sektor ekonomi yang secara tidak langsung menggambarkan tingkat pertumbuhan yang terjadi dan sebagai indikator penting bagi daerah untuk mengevaluasi keberhasilan pembangunan (Sirojuzilam, 2008:18). Tujuan utama dari pembangunan ekonomi adalah untuk menciptakan kesejahteraan masyarakat di daerahnya. Untuk mencapai tujuan pembangunan daerah maka daerah harus mampu mengidentifikasi dengan baik potensi ekonomi daerah yang dimiliki dan mengelolanya dengan baik. Pertumbuhan ekonomi dan prosesnya yang berkelanjutan merupakan kondisi utama bagi kelangsungan pembangunan ekonomi daerah. Pertumbuhan ekonomi dapat ditunjukkan dari besarnya pendapatan Produk Domestik Regional Bruto (Afzal, 2007). Karena jumlah penduduk terus bertambah dan berarti kebutuhan ekonomi juga bertambah, sehingga dibutuhkan penambahan pendapatan melalui peningkatan output agregat (barang dan jasa) atau Produk Domestik Regional Bruto (PDRB) setiap tahun (Tambunan, 2001).

Kabupaten Padangpariaman merupakan salah satu daerah Kabupaten di Provinsi Sumatera Barat yang mempunyai wilayah cukup luas. Letak yang strategis dan memiliki banyak potensi sumber daya alam untuk meningkatkan pertumbuhan ekonomi. Laju pertumbuhan ekonomi Kabupaten Padangpariaman selama kurun waktu 20112016 mengalami pertumbuhan di atas laju pertumbuhan Provinsi Sumatera Barat Hal ini bisa terlihat pada grafik 1 .

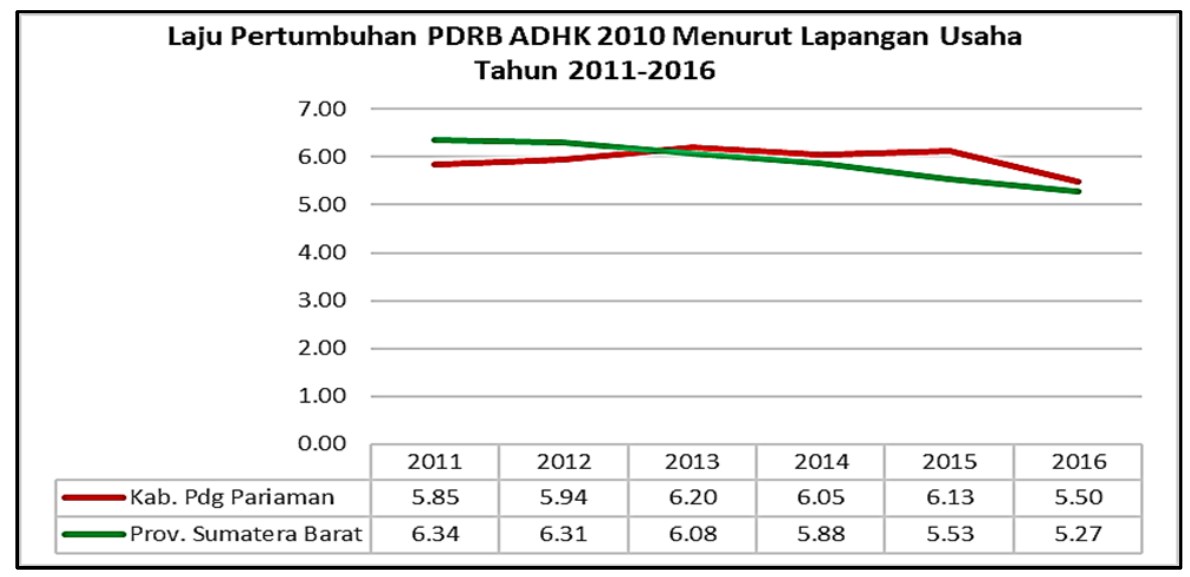

\section{Grafik 1}

Perbandingan Laju pertumbuhan Ekonomi Kabupaten Padangpariaman dan Provinsi Sumatera Barat 2010-2016 ( Sumber: BPS Prop. Sumatera Barat) 
Dari grafik 1 terlihat bahwa tingkat pertumbuhan ekonomi di wilayah kabupaten dan provinsi rata-rata berkisar 5-6 persen per tahun. Tingkat pertumbuhan Rata-rata laju pertumbuhan ekonomi Kabupaten Padangpariaman dalam kurun waktu 20112016 adalah sebesar 5,94 lebih tinggi sedikit daripada pertumbuhan ekonomi Provinsi Sumatera Barat yaitu sebesar 5.90 persen.

Salah satu langkah dalam mendorong dan meningkatkan pertumbuhan ekonomi adalah dengan meningkatkan potensi dari berbagai sektor agar dapat mendorong pembangunan ekonomi (Aryanti, 2009) dalam (Savitri Dewi, Yasa, 2018). Pertumbuhan ekonomi daerah pada dasarnya dipengaruhi oleh keunggulan komparatif suatu daerah, spesialisasi wilayah, serta potensi ekonomi yang dimiliki oleh daerah tersebut. Oleh karena itu, pemanfaatan dan pengembangan seluruh potensi ekonomi menjadi prioritas utama yang harus digali dan dikembangkan dalam melaksanakan pembangunan ekonomi daerah secara berkelanjutan (Arsyad, 1999 dalam Hajeri, Yurisinthae, Dolorosa, 2015)

Pelaksanaan otonomi daerah dengan pemberdayaan potensi daerah akan berjalan dengan baik jika sektor unggulan daerah dapat dioptimalkan, di mana sektor unggulan ini penting untuk menentukan skala prioritas dalam pembangunan. Tujuan penelitian ini mencoba menggambarkan pola perubahan dan pertumbuhan sektoral dalam perekonomian, menentukan sektor-sektor basis dan Nonbasis, serta perubahan dan pergeseran struktur perekonomian daerah sehingga dapat dijadikan pertimbangan dalam perumusan kebijakan dan perencanaan pembangunan di Kabupaten Padangpariaman.

\section{TINJAUAN PUSTAKA}

\section{Sektor Unggulan}

Kontribusi terbesar terhadap kemajuan ekonomi daerah merupakan prioritas kebijakan yang harus dilaksanakan Oleh karena itu, informasi mengenai potensipotensi yang dimiliki daerah sangat penting diperlukan untuk mendukung kebijakan pembangunan ekonomi daerah (Rini, 2006) (dalam Erawati, Yasa, 2011). Sektor unggulan perekonomian adalah sektor yang memiliki ketangguhan dan kemampuan tinggi sehingga dapat dijadikan sebagai tumpuan harapan pembangunan ekonomi. Sektor unggulan merupakan tulang punggung dan penggerak perekonomian, sehingga dapat juga disebut sebagai sektor kunci atau sektor pemimpin perekonomian suatu wilayah. Dengan demikian, sektor unggulan merupakan refleksi dari suatu struktur perekonomian, sehingga dapat pula dipandang sebagai salah satu aspek penciri atau karakteristik dari suatu perekonomian (Deptan, 2005 dalam Hajeri, Yurisinthae, Dolorosa, 2015)

Kriteria sektor unggulan akan sangat bervariasi. Hal ini didasarkan atas seberapa besar peranan sektor tersebut dalam perekonomian daerah, di antaranya: pertama, sektor unggulan tersebut memiliki laju tumbuh yang tinggi; kedua, sektor tersebut memiliki angka penyerapan tenaga kerja yang relatif besar; ketiga, sektor tersebut memiliki keterkaitan antarsektor yang tinggi baik ke depan maupun ke belakang; keempat, dapat juga di artikan sebagai sektor yang mampu menciptakan nilai tambah yang tinggi Sambodo dalam (Usya, 2006)

\section{Teori Pertumbuhan Jalur Cepat (Turnpike)}

Teori Pertumbuhan Jalur Cepat (TPJC) atau turnpike diperkenalkan oleh Samuelson (1955). Pada intinya teori ini menekankan bahwa setiap daerah perlu mengetahui sektor ataupun komoditas apayang memilikipotensi besar dan dapat dikembangkan dengan cepat, baik karena potensi alam maupun karena sektor itu memiliki comparative adventage untuk dikembangkan. Artinya, dengan kebutuhan modal yang sama sektor 
tersebut dapat memberikan nilai tambah yang lebih besar, dapat berproduksi dalam waktu relatif singkat dan sumbangan untuk perekonomian juga cepat besar (Hajeri, Yurisinthae, Dolorosa, 2015) Pengembangan sektor tersebut akan mendorong sektor lainnya untuk berkembang. Menggabungkan kebijakan jalur cepat dan menyinergikannya dengan sektor yang terkait akan mampu membuat perekonomian tumbuh cepat.

\section{Produk Domestik Regional Bruto}

Keberhasilan pembangunan ekonomi suatu wilayah dapat dilihat dari perubahan Produk Domestik Regional Bruto (PDRB). Data PDRB merupakan informasi yang sangat penting untuk mengetahui output pada sektor ekonomi dan melihat pertumbuhan di suatu wilayah tertentu (provinsi/kabupaten/ kota). Peranan masing-masing sektor terhadap pembentukan PDRB suatu daerah mencerminkan kecenderungan struktur ekonomi daerah tersebut. Perubahan struktur perekonomian yang terjadi umumnya bergerak dari sektor pertanian menuju industri dan selanjutnya ke sektor jasa (Makmun dan Irwansyah, 2013 dalam Abidin, 2015).

\section{Typology Klassen}

Analisis Tipologi Klasen dapat digunakan dalam menganalisis pengelompokan potensi, pola dan struktur pertumbuhan masing-masing sektor ekonomi di suatu wilayah (Sjafrizal, 2014, p. 202). Analisis ini bertujuan untuk mengidentifikasi dan mengetahui klasifikasi sektor perekonomian di Kabupaten Padangpariaman.

Tabel 1. Kriteria Struktur dan Pertumbuhan Sektor-sektor Ekonomi Wilayah menurut Typology Klassen

\begin{tabular}{|c|c|c|}
\hline \multirow{2}{*}{ Laju Pertumbuhan } & \multicolumn{2}{|c|}{ Kontribusi } \\
\hline & $r_{i j}>r_{i n}$ & $r_{i j}<r_{i n}$ \\
\hline $\begin{array}{c}\text { Kontribusi besar } \\
\text { (Kij > Kin ) }\end{array}$ & $\begin{array}{c}\text { Kuadran I } \\
\text { Sektor Andalan/Prima }\end{array}$ & $\begin{array}{c}\text { Kuadran II } \\
\text { Sektor Potensial }\end{array}$ \\
\hline $\begin{array}{c}\text { Kontribusi kecil } \\
\text { (Kij < Kin ) }\end{array}$ & $\begin{array}{c}\text { Kuadran III } \\
\text { Sektor berkembang }\end{array}$ & $\begin{array}{c}\text { Kuadran IV } \\
\text { Sektor relatif tertinggal }\end{array}$ \\
\hline
\end{tabular}

Sumber: (Syafrizal, 2008, p. 18)

Keterangan:

$r_{\text {ij }} \quad$ : pertumbuhan sektor i di Kabupaten Padangpariaman;

$r_{\text {in }} \quad$ : pertumbuhan sektor i di Provinsi Sumatera Barat;

$\mathrm{K}_{\mathrm{ij}} \quad$ : kontribusi sektor i pada PDRB Kabupaten Padangpariaman;

$\mathrm{K}_{\text {in }} \quad$ : kontribusi sektor i pada PDRB Provinsi Sumatera Barat.

\section{- Location Quotient (LQ)}

Analisis Location Quotient (LQ) merupakan suatu analisis yang digunakan untuk mengetahui tingkat konsentrasi kegiatan ekonomi/basis ekonomi pada suatu daerah atau wilayah tertentu yang dinilai terutama dari kriteria kontribusi yang diberikan (Sjafrizal, 2014:188), Analisis LQ dihitung melalui perbandingan relatif sumbangan nilai tambah sebuah sektor di suatu daerah (Kabupaten/Kota) terhadap sumbangan nilai tambah sektor yang bersangkutan dalam skala provinsi atau nasional (Yolamalinda, 2014). LQ $>1$ artinya peranan suatu sektor di daerah lebih menonjol daripada peranan sektor tersebut di wilayah induknya. Ini juga merupakan petunjuk adanya keunggulan komparatif di mana daerah tersebut surplus akan produk sektor i dan mengekspornya ke daerah lain (Tarigan, 2012).

Untuk mendapatkan nilai LQ menggunakan metode yang mengacu pada 
formula yang dikemukakan oleh Bendavid-Val dalam (Kuncoro, 2004:183) sebagai berikut.

$$
\mathrm{LQ}=\left(\mathrm{PDRB}_{\mathrm{PP}} / \sum \mathrm{PDRB} \mathrm{PP}_{\mathrm{P}}\right) /\left(\mathrm{PDRB}_{\mathrm{SBR}} / \sum \mathrm{PDRB}_{\mathrm{SBR}}\right)
$$

\section{Keterangan:}

$$
\begin{aligned}
& \mathrm{PDRB}_{\mathrm{PPi}}=\text { PDRB sektor i di Kabupaten Padangpariaman tahun i } \\
& \sum \mathrm{PDRB}_{\mathrm{PP}}=\text { Total PDRB di Kabupaten Padangpariaman tahun i } \\
& \mathrm{PDRB}_{\mathrm{SBR}, \mathrm{i}}=\text { PDRB sektor i di Prov. Sumatera Barat tahun i } \\
& \sum \mathrm{PDRB}_{\mathrm{SBR}}=\text { Total PDRB di Prov. Sumatera Barat tahun i }
\end{aligned}
$$

\section{- Dynamic Location Quotient (DLQ)}

Menurut Suyatno (2000 dalam Hajeri, dkk., 2015) rumus dari $D L Q$ sebagai berikut.

$$
\text { DLQ }=\left[\frac{(1+\mathrm{gij}) /(1+\mathrm{gj})}{(\mathbf{1}+\mathrm{Gi}) /(1+\mathrm{G})}\right]^{\mathrm{t}}
$$

Nilai $D L Q>1$ berarti suatu sektor masih dapat diharapkan untuk menjadi sektor basis, sedangkan dengan nilai $D L Q<1$, sektor tersebut tidak dapat diharapkan untuk menjadi sektor basis pada masa yang akan datang.

\section{- Analisis Shift Share}

Analisis Shift Share merupakan salah satu teknis analisis untuk mengetahui faktorfaktor utama yang memengaruhi dan menentukan pertumbuhan ekonomi pada suatu daerah (Sjafrizal, 2014: 189). Menurut Arsyad (1999: 314) (dalam Yulianita, 2010) analisis "shift share" merupakan teknik yang sangat berguna dalam menganalisis perubahan struktur ekonomi daerah dibandingkan dengan perekonomian nasional juga untuk mengetahui perubahan dan pergeseran sektor perekonomian wilayah. Hasil analisis akan menggambarkan kinerja sektorsektor dalam PDRB Kabupaten Padangpariaman dibandingkan wilayah Provinsi Sumatera Barat. Apabila penyimpangan positif, maka dikatakan suatu sektor dalam PDRB memiliki keunggulan kompetitif atau sebaliknya. ekonomi dan pembangunan di daerah. Metode shift.

Menurut Soepono dalam (Hajeri, Yurisinthae, Dolorosa, 2015) persamaan dan komponen komponennya dalam analisis shift share sebagai berikut.

$$
\mathrm{Dij}=\mathrm{Nij}+\mathrm{Mij}+\mathrm{Cij}
$$

\section{Keterangan:}

$$
\begin{array}{ll}
\mathrm{i} & =\text { Sektor-sektor ekonomi yang diteliti } \\
\mathrm{j} & =\text { Variabel wilayah Kabupaten Padangpariaman } \\
\mathrm{Dij} & =\text { Perubahan sektor } \mathrm{i} \text { di daerah } \mathrm{j} \\
\mathrm{Nij} & =\text { Pertumbuhan sektor } \mathrm{i} \text { di daerah } \mathrm{j} \\
\mathrm{Mij} & =\text { Bauran industri sektor } \mathrm{i} \text { di daerah } \mathrm{j} \\
\mathrm{Cij} & =\text { Keunggulan kompetitif sektor } i \text { di daerah } j
\end{array}
$$

Variabel yang digunakan pada penelitian ini adalah nilai tambah yang dinotasikan sebagai (E) sehingga persamaannya sebagai berikut. 


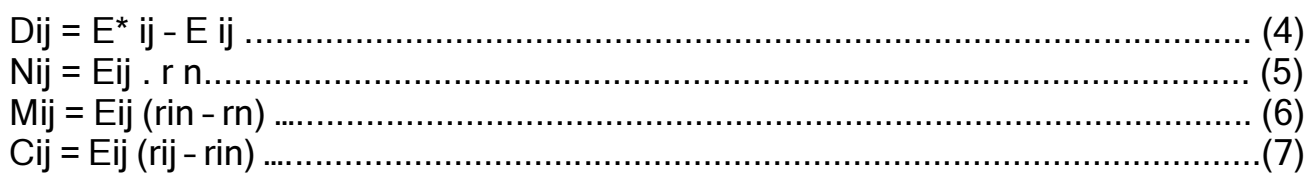

Sehingga di dapat persamaan shift share untuk sektor $i$ di wilayah $j$ (Soepomo, 1993) sebagai berikut.

$$
\mathrm{Dij}=(\mathrm{E} i j . \mathrm{r} n)+(\mathrm{E} i j(\mathrm{r} i n-\mathrm{r} n))+(\mathrm{E} i j(\mathrm{r} i j-\mathrm{r} i n))
$$

\section{- Metode Overlay}

Analisis Overlay digunakan untuk mendeskripsikan kegiatan ekonomi yang potensial, dengan menggunakan kriteria pertumbuhan dan kriteria keunggulan komparatif. (Suyana Utama, 2010: 67) (Ni Made, Yasa, 2018).

Menurut Basuki dan Gayatri, (2009) dan Wahyuningtyas, dkk (2013), Penentuan sektor unggulan dilakukan dengan melihat overlay (gabungan) dari penghitungan LQ dan DLQ, Shift Share dan Tipology Klassen. Koefisien dari ketiga komponen disamakan dengan memberi tanda positif $(+)$ dan negatif (-). Yang berarti: 1) Nilai positif jika Gabungan LQ dan DLQ lebih dari 1 dan negatif kurang dari 1,2) pada Shift Share nilai Proportional dan Differential Shift keduanya sama-sama positif dan negatif jika salah satu atau keduanya negatif, 3) Tipology Klassen bernilai positif jika sektor tersebut berada di kuadran 1 dan negatif jika bukan dikuadran 1. Jika hasil Identifikasi overlay tersebut jika ketiganya positif (+++) maka dapat dikatakan bahwa sektor tersebut merupakan sektor unggulan.

\section{METODE PENELITIAN}

\section{Lokasi Penelitian dan Sumber Data}

Analisis data dalam penelitian ini dilakukan secara deskriptif kuantitatif. Kegiatan penelitian ini dilakukan secara purposive di wilayah Kabupaten Padangpariaman Provinsi Sumatera Barat

\section{Teknik Pengumpulan dan Sumber Data}

Jenis data yang digunakan merupakan data sekunder yaitu data time series (runtut waktu) dari Produk Domestik Regional Bruto (PDRB Atas Dasar Harga Konstan 2010 tahun 2011-2016. Data di peroleh dari website badan pusat statistik (bps) provinsi sumatera barat dan bps Kabupaten Padangpariaman.

\section{Alat Analisis}

Desain dan metode pendekatan, pengkajian serta proses untuk penentuan sektor unggulan dan struktur ekonomi di Kabupaten Padangpariaman tahun 2011-2016 menggunakan metode analisis Typology Klassen, Location Quotient (LQ) Dynamic Location Quotient (DLQ), Analisis Shift Share dan Metode Overlay

\section{ANALISIS DAN PEMBAHASAN}

\section{Klasifikasi Typology Klassen}

Hasil analisis Tipologi Klassen menunjukkan posisi pertumbuhan dan pangsa sektor, subsektor, usaha, atau komoditi pembentuk variabel regional suatu daerah. Analisis ini dapat digunakan sebagai acuan pendukung untuk menentukan prioritas dalam pengembangan daerah. 
Tabel 2. Hasil Perhitungan Tipologi Klassen Kabupaten Padangpariaman Berdasarkan Sektor Ekonomi Tahun 2011-2016

\begin{tabular}{|c|c|c|}
\hline \multirow{2}{*}{ Laju Pertumbuhan } & \multicolumn{2}{|c|}{ Kontribusi } \\
\hline & $R_{i j}>r_{i n}$ & $R_{i j}<r_{i n}$ \\
\hline $\begin{array}{l}\text { Kontribusi besar } \\
\qquad(\text { Kij > Kin ) }\end{array}$ & $\begin{array}{l}\text { Sektor Andalan/Prima } \\
\text { - Pertambangan dan Penggalian } \\
\text { - Industri pengolahan }\end{array}$ & $\begin{array}{l}\text { Sektor Potensial } \\
\text { - Transportasi dan Pergudangan } \\
\text { - Jasa Pendidikan } \\
\end{array}$ \\
\hline $\begin{array}{c}\text { Kontribusi kecil } \\
\text { ( Kij < Kin ) }\end{array}$ & $\begin{array}{l}\quad \text { Sektor berkembang } \\
\text { - Pertanian, Kehutanan \& Perikanan } \\
\text { - Perdagangan Besar dan Eceran; Reparasi Mobil } \\
\text { dan Spd. Motor } \\
\text { - Informasi dan Komunikasi } \\
\text { - Jasa Perusahaan } \\
\text { - Adm.Pemerintahan, Pertahanan \& Jaminan Sosial } \\
\text { Wajib } \\
\text { - Jasa Kesehatan dan Keg. Sosial }\end{array}$ & $\begin{array}{l}\text { Sektor relatif tertinggal } \\
\text { - Pengadaan Listrik dan Gas } \\
\text { - Pengadaan Air, Peng. Sampah, Limbah \& Daur } \\
\text { Ulang } \\
\text { - Konstruksi } \\
\text { - Penyediaan Akomodasi dan Makan Minum } \\
\text { - Jasa Keuangan dan Asuransi } \\
\text { - Real Estate } \\
\text { - Jasa lainnya }\end{array}$ \\
\hline
\end{tabular}

Sumber : Data diolah

\section{Klasifikasi Sektor Ekonomi (Sektor Basis dan Nonbasis) Kabupaten Padangpariaman.}

\section{- Location Quotient (LQ)}

Teori Location Question, seperti dikemukakan Bendavid (1991), digunakan untuk menganalisis keragaman basis ekonomi. Berdasarkan analisis tersebut dapat diidentifikasi sektor-sektor apa saja yang dapat dikembangkan untuk tujuan sektor dan tujuan menyuplai kebutuhan lokal, sehingga sektor yang dikatakan potensial dapat dijadikan sektor prioritas utama dalam perencanaan pembangunan ekonomi (Hajeri, Yurisinthae, Dolorosa, 2015).

Hasil perhitungan dengan metode Location Quotient (LQ) terhadap data PDRB ADHK 2010 Tahun 2011-2016 seperti terlihat pada tabel 3 .

Tabel 3. Hasil Perhitungan Location Quotient (LQ) Kabupaten Padangpariaman Tahun 2011-2016

\begin{tabular}{|l|c|c|c|c|c|c|c|c|}
\hline \multirow{2}{*}{\multicolumn{1}{|c|}{ Lapangan Usaha }} & \multicolumn{4}{c|}{ Nilai LQ } & Rerata & \multirow{2}{*}{ Ket } \\
\cline { 2 - 7 } & 2011 & 2012 & 2013 & 2014 & 2015 & 2016 & LQ & \\
\hline Pertanian, Kehutanan, dan Perikanan & 0.90 & 0.91 & 0.91 & 0.91 & 0.91 & 0.91 & 0.91 & Nonbasis \\
\hline Pertambangan dan Penggalian & 1.31 & 1.30 & 1.29 & 1.32 & 1.35 & 1.35 & 1.32 & Basis \\
\hline Industri Pengolahan & 1.18 & 1.19 & 1.15 & 1.15 & 1.22 & 1.21 & 1.18 & Basis \\
\hline Pengadaan Listrik dan Gas & 0.29 & 0.30 & 0.29 & 0.28 & 0.28 & 0.28 & 0.29 & Nonbasis \\
\hline Pengadaan Air, Pengelolaan Sampah, Limbah\&Daur Ulang & 0.52 & 0.51 & 051 & 0.51 & 0.50 & 0.50 & 0.51 & Nonbasis \\
\hline Konstruksi & 0.92 & 0.91 & 0.92 & 0.93 & 0.92 & 0.89 & 0.92 & Nonbasis \\
\hline Perdagangan Besar dan Eceran; Rep. Mobil dan Spd Motor & 0.63 & 0.62 & 0.62 & 0.64 & 0.64 & 0.64 & 0.63 & Nonbasis \\
\hline Transportasi dan Pergudangan & 2.10 & 2.10 & 2.01 & 1.94 & 1.94 & 1.96 & 2.01 & Basis \\
\hline Penyediaan Akomodasi dan Makan Minum & 0.80 & 0.80 & 0.79 & 0.78 & 0.78 & 0.76 & 0.78 & Nonbasis \\
\hline Informasi dan Komunikasi & 0.57 & 0.57 & 0.58 & 0.58 & 0.58 & 0.58 & 0.58 & Nonbasis \\
\hline Jasa Keuangan dan Asuransi & 0.52 & 0.52 & 0.52 & 0.53 & 0.53 & 0.52 & 0.52 & Nonbasis \\
\hline Real Estate & 0.53 & 0.49 & 0.49 & 0.52 & 0.52 & 0.51 & 0.51 & Nonbasis \\
\hline Jasa Perusahaan & 0.18 & 0.18 & 0.19 & 0.18 & 0.19 & 0.19 & 0.19 & Nonbasis \\
\hline Administrasi Pemerintahan, Pertahanan dan Jamsos. Wajib & 0.82 & 0.84 & 0.90 & 0.90 & 0.89 & 0.89 & 0.87 & Nonbasis \\
\hline Jasa Pendidikan & 1.24 & 1.23 & 1.23 & 1.22 & 1.21 & 1.21 & 1.22 & Basis \\
\hline Jasa Kesehatan dan Keg.Sosial & 0.43 & 0.43 & 0.43 & 0.43 & 0.43 & 0.44 & 0.43 & Nonbasis \\
\hline Jasa lainnya & 0.75 & 0.75 & 0.76 & 0.76 & 0.73 & 0.73 & 0.74 & Nonbasis \\
\hline
\end{tabular}

Sumber: Data diolah.

Berdasarkan Tabel 3, teridentifikasi empat sektor perekonomian yang tergolong sektor basis dengan nilai LQ>1 di Kabupaten
Padangpariaman, yaitu: sektor Transportasi dan Pergudangan sebagai peringkat teratas dengan nilai koefisien LQ sebesar 2,01, 
dan diikuti oleh sektor Pertambangan dan Penggalian dengan nilai 1,32, sektor Pendidikan sebesar 1,22 dan terakhir sektor industri pengolahan dengan nilai koefisien sebesar 1,18. Keempat sektor basis ini memperlihatkan keunggulan kompetitif dan nilai kontribusi yang besar dalam perekonomian Kabupaten Padangpariaman karena telah mampu bersaing dengan kabupaten/kota lain di Sumatera Barat.

\section{- Dynamic Location Quotient (DLQ)}

Analisis Dynamic Locationt Quotient (DLQ) digunakan untuk menentukan reposisi sektor dan sub sektor ke depan di daerah tertentu. Analisis ini penting digunakan untuk mengetahui apakah di masa yang akan datang sektor dan sub sektor tertentu dapat bertahan sebagai sektor dan sub sektor basis atau tidak dan sebaliknya apakah sektor dan sub sektor yang sebelumnya bukan basis dapat mengalami reposisi/berpotensi menjadi sektor dan sub sektor basis di masa yang akan datang.

Tabel 4 Hasil Perhitungan Dynamic Location Quotient (DLQ) Kabupaten Padangpariaman Tahun 2011-2016

\begin{tabular}{|l|c|c|c|c|c|c|c|l|}
\hline \multirow{2}{*}{ Lapangan Usaha } & \multicolumn{5}{|c|}{ Nilai DLQ } & \multirow{2}{*}{$\begin{array}{c}\text { Rerata } \\
\text { DLQ }\end{array}$} & Ket \\
\cline { 2 - 8 } & 2011 & 2012 & 2013 & 2014 & 2015 & 2016 & \\
\hline Pertanian, Kehutanan\&Perikanan & 0.70 & 1.07 & 1.01 & 1.12 & 0.97 & 1.11 & 1.00 & Basis \\
\hline Pertambangan dan Penggalian & 0.32 & 0.82 & 0.92 & 1.50 & 1.47 & 1.03 & 1.01 & Basis \\
\hline Industri Pengolahan & 1.06 & 1.07 & 1.40 & 1.03 & 1.12 & 0.86 & 1.09 & Basis \\
\hline Pengadaan Listrik dan Gas & 1.36 & 1.52 & 0.52 & 0.83 & 0.91 & 0.95 & 1.02 & Basis \\
\hline Pengadaan Air, Peng. Sampah, Limbah \& Daur Ulang & 0.71 & 0.56 & 0.95 & 1.07 & 0.81 & 0.98 & 0.85 & Nonbasis \\
\hline Konstruksi & 0.97 & 0.89 & 1.06 & 1.17 & 0.80 & 0.59 & 0.91 & Nonbasis \\
\hline $\begin{array}{l}\text { Perdagangan Besar dan Eceran; Rep. Mobil dan Spd } \\
\text { Motor }\end{array}$ & 0.87 & 0.80 & 1.07 & 1.38 & 0.98 & 1.07 & 1.03 & Basis \\
\hline Transportasi dan Pergudangan & 1.32 & 1.03 & 0.51 & 0.55 & 1.00 & 1.13 & 0.92 & Nonbasis \\
\hline Penyediaan Akomodasi dan Makan Minum & 0.64 & 0.88 & 0.79 & 0.99 & 0.91 & 0.72 & 0.82 & Nonbasis \\
\hline Informasi dan Komunikasi & 0.96 & 1.04 & 1.18 & 1.10 & 0.95 & 0.99 & 1.04 & Basis \\
\hline Jasa Keuangan dan Asuransi & 1.01 & 1.04 & 1.10 & 1.20 & 1.07 & 0.65 & 1.01 & Basis \\
\hline Real Estate & 1.00 & 0.96 & 1.01 & 1.00 & 0.84 & 0.81 & 0.94 & Nonbasis \\
\hline Jasa Perusahaan & 1.52 & 1.40 & 1.12 & 0.88 & 1.12 & 1.23 & 1.21 & Basis \\
\hline $\begin{array}{l}\text { Administrasi Pemerintahan, Pertahanan dan Jamsos. } \\
\text { Wajib }\end{array}$ & 0.88 & 3.24 & 3.48 & 1.13 & 0.83 & 0.95 & 1.75 & Basis \\
\hline Jasa Pendidikan & 1.04 & 0.93 & 0.92 & 0.98 & 0.83 & 1.00 & 0.95 & Nonbasis \\
\hline Jasa Kesehatan dan Kegiatan Sosial & 1.07 & 1.05 & 0.99 & 1.03 & 0.81 & 1.27 & 1.04 & Basis \\
\hline Jasa lainnya & 0.91 & 1.05 & 1.11 & 1.00 & 0.63 & 0.97 & 0.94 & Nonbasis \\
\hline
\end{tabular}

Sumber : Data diolah

Berdasarkan hasil perhitungan DLQ pada Tabel 4, terdapat sepuluh sektor pembentuk PDRB Kabupaten Padangpariaman yang diharapkan akan menjadi sektor sektor basis di masa yang akan datang karena memiliki nilai DLQ>1. Nilai terbesar dimiliki oleh sektor Administrasi Pemerintahan,
Pertahanan dan Jaminan Sosial Wajib dengan nilai koefisien sebesar 1,74 dan sektor jasa perusahaan sebesar 1,21, sektor-sektor tersebut pada awal perhitungan LQ belum menjadi sektor basis. Namun pada masa datang mengalami reposisi menjadi sektor basis. 
Penentuan sektor dan sub sektor basis saat ini dan pada masa yang akan datang dapat digunakan dengan metode analisis gabungan $L Q$ dan $D L Q$. Hasil hitungan gabungan LQ dan DLQ dapat terlihat pada tabel 5 .

Tabel 5. Hasil Analisis LQ dan DLQSektor dan Sub Sektor Perekonomian di Kabupaten Padangpariaman Tahun 2011-2016

\begin{tabular}{|c|c|c|c|c|}
\hline No & Lapangan Usaha & Rerata LQ & Rerata DLQ & Keterangan \\
\hline$A$ & Pertanian, Kehutanan, dan Perikanan & 0.91 & 1.00 & Reposisi Basis \\
\hline B & Pertambangan dan Penggalian & 1.32 & 1.01 & Basis \\
\hline C & Industri Pengolahan & 1.19 & 1.09 & Basis \\
\hline $\mathrm{D}$ & Pengadaan Listrik dan Gas & 0.29 & 1.02 & Reposisi Basis \\
\hline$E$ & $\begin{array}{l}\text { Pengadaan Air, Pengelolaan Sampah, Limbah dan } \\
\text { Daur Ulang }\end{array}$ & 0.51 & 0.85 & Nonbasis \\
\hline $\mathrm{F}$ & Konstruksi & 0.92 & 0.91 & Nonbasis \\
\hline G & $\begin{array}{l}\text { Perdagangan Besar dan Eceran; Reparasi Mobil dan } \\
\text { Sepeda Motor }\end{array}$ & 0.63 & 1.03 & Reposisi Basis \\
\hline $\mathrm{H}$ & Transportasi dan Pergudangan & 2.01 & 0.92 & Reposisi Nonbasis \\
\hline I & Penyediaan Akomodasi dan Makan Minum & 0.79 & 0.82 & Nonbasis \\
\hline$J$ & Informasi dan Komunikasi & 0.58 & 1.04 & Reposisi Basis \\
\hline $\mathrm{K}$ & Jasa Keuangan dan Asuransi & 0.53 & 1.01 & Reposisi Basis \\
\hline L & Real Estate & 0.52 & 0.94 & Nonbasis \\
\hline $\mathrm{M}, \mathrm{N}$ & Jasa Perusahaan & 0.19 & 1.21 & Reposisi Basis \\
\hline 0 & Adm. Pemerintahan, Pertahanan dan Jamsos Wajib & 0.88 & 1.75 & Reposisi Basis \\
\hline$P$ & Jasa Pendidikan & 1.23 & 0.95 & Reposisi Nonbasis \\
\hline Q & Jasa Kesehatan dan Kegiatan Sosial & 0.44 & 1.04 & Reposisi Basis \\
\hline$R, S, T, U$ & Jasa lainnya & 0.75 & 0.94 & Nonbasis \\
\hline
\end{tabular}

Sumber : Data diolah

Hasil analisis gabungan $L Q$ dan $D L Q$ yang menunjukkan nilai $L Q$ Nonbasis dan pada nilai $D L Q$ basis, berarti sektor tersebut mengalami reposisi menjadi sektor basis di masa yang akan datang (reposisi basis). Sebaliknya, jika nilai $L Q$ basis dan pada nilai $D L Q$ Nonbasis, maka dapat diartikan sektor tersebut mengalami reposisi menjadi sektor Nonbasis pada masa yang akan datang (reposisi Nonbasis).

Berdasarkan Tabel 5 terdapat delapan sektor yang mengalami reposisi dari Nonbasis menjadi sektor basis di masa yang akan datang, yaitu 1) sektor Pertanian, Kehutanan, dan Perikanan, 2) sektor Pengadaan Listrik dan Gas, 3) sektor Perdagangan Besar dan Eceran; Reparasi
Mobil dan Sepeda Motor, Perdagangan Besar dan Eceran; 4) sektor Informasi dan Komunikasi, 5) sektor Jasa Keuangan dan Asuransi \& jasa perusahaan, 6) sektor Jasa Perusahaan, 7) sektor Administrasi Pemerintahan, Pertahanan dan Jaminan sosial Wajib dan 8) sektor Jasa Kesehatan dan Kegiatan Sosial. Selain itu, terdapat dua sektor basis di Kabupaten Padangpariaman saat ini dan pada masa yang akan datang yaitu sektor Pertambangan dan Penggalian, dan sektor Industri Pengolahan. Adapun sektor yang akan tetap menjadi sektor Nonbasis di masa yang akan datang adalah sektor Pengadaan Air, Pengelolaan Sampah, Limbah dan Daur Ulang, sektor Konstruksi, Penyediaan Akomodasi dan Makan Minum, Real Estate dan sektor Jasa lainnya. 


\section{Analisis Struktur Ekonomi: Shift Share}

Kinerja berbagai sektor perekonomian dapat dilihat melalui PDRB Kabupaten Padangpariaman yang dibandingkan dengan PDRB Provinsi Sumatera Barat dengan mengacu pada tahun dasar dan tahun akhir analisis. Analisis Shift-Share Klasik mengasumsikan bahwa perubahan relatif struktur atau kinerja perekonomian Kabupaten Padangpariaman dipengaruhi oleh struktur perekonomian dari Provinsi Sumatera Barat dari beberapa komponen yaitu Pertumbuhan ekonomi wilayah (Nij), Bauran industri (Mij), dan Keunggulan Kompetitif (Cij). Perhitungannya dapat dilihat pada tabel 6 .

Tabel 6. Hasil Perhitungan Shift Share Kab Padangpariaman 2010-2016

\begin{tabular}{|c|c|c|c|c|c|}
\hline No. & Sektor/Industri & $\mathrm{Nij}$ & Mij & $\mathrm{Cij}$ & Dij \\
\hline A & Pertanian, Kehutanan, dan Perikanan & $662,106.22$ & $(257,815.85)$ & $46,162.63$ & $450,453.00$ \\
\hline B & Pertambangan dan Penggalian & $169,374.02$ & $(41,473.38)$ & $21,323.36$ & $149,224.00$ \\
\hline C & Industri Pengolahan & $391,303.44$ & $(82,279.34)$ & $43,347.90$ & $352,372.00$ \\
\hline $\mathrm{D}$ & Pengadaan Listrik dan Gas & 802.02 & 416.32 & $(27.34)$ & $1,191.00$ \\
\hline $\mathrm{E}$ & $\begin{array}{l}\text { Pengadaan Air, Peng. Sampah, Limbah \& Daur } \\
\text { Ulang }\end{array}$ & $1,582.17$ & $(251.40)$ & $(150.78)$ & $1,180.00$ \\
\hline $\mathrm{F}$ & Konstruksi & $212,040.11$ & $93,778.67$ & $(28,824.78)$ & $276,994.00$ \\
\hline G & Perdagangan Besar dan Eceran; Rep.Mobil\&Spd mtr & $273,105.04$ & $23,036.36$ & $23,514.60$ & $319,656.00$ \\
\hline $\mathrm{H}$ & Transportasi dan Pergudangan & $638,119.35$ & $289,737.18$ & $(162,765.53)$ & $765,091.00$ \\
\hline I & Penyediaan Akomodasi \& Makan Minum & $23,089.20$ & $4,510.02$ & $(4,481.22)$ & $23,118.00$ \\
\hline $\mathrm{J}$ & Informasi dan Komunikasi & $91,910.26$ & $70,822.71$ & $15,514.03$ & $178,247.00$ \\
\hline $\mathrm{K}$ & Jasa Keuangan dan Asuransi & $44,442.16$ & $5,140.05$ & $(150.21)$ & $49,432.00$ \\
\hline L & Real Estate & $30,370.39$ & $(3,159.46)$ & $(1,954.93)$ & $25,256.00$ \\
\hline$M, N$ & Jasa Perusahaan & $2,276.47$ & 177.10 & 535.43 & $2,989.00$ \\
\hline 0 & Administrasi Pemerintahan, Pertahanan\&Jamsos wjb & $152,262.60$ & $(83,681.90)$ & $49,393.30$ & $117,974.00$ \\
\hline $\mathrm{P}$ & Jasa Pendidikan & $116,684.78$ & $56,236.40$ & $(11,491.18)$ & $161,430.00$ \\
\hline Q & Jasa Kesehatan dan Kegiatan Sosial & $15,206.09$ & $6,151.33$ & 981.58 & $22,339.00$ \\
\hline \multirow[t]{2}{*}{$\mathrm{R}, \mathrm{S}, \mathrm{T}, \mathrm{U}$} & Jasa lainnya & $32,845.13$ & $12,588.06$ & $(3,055.55)$ & $42,377.63$ \\
\hline & PDRB & $2,857,519.46$ & $93,932.87$ & $(12,128.70)$ & $2,939,323.63$ \\
\hline
\end{tabular}

Sumber: Data diolah

Dari hasil analisis pada tabel di atas diketahui bahwa selama kurun waktu 20112016 PDRB Kabupaten Padangpariaman mengalami pertambahan nilai absolut atau mengalami kenaikan kinerja perekonomian daerah sebesar Rp 2,939,323.63 juta rupiah. Peningkatan terbesar terjadi pada sektor Transportasi dan Pergudangan, sektor pertanian dan sektor industri pengolahan dengan nilai pertumbuhan riil sektor masing-masing sebesar 765,091 juta rupiah, 450.453 juta rupiah, dan 352.372 juta rupiah. Peningkatan pertumbuhan nilai PDRB sektor perekonomian di Kabupaten Padangpariaman salah satunya dipengaruhi oleh pertumbuhan PDRB sektor Perekonomian Provinsi Sumatera Barat (Nij). Selama periode 2011-2016, Pertumbuhan tiga sektor terbesar tersebut di Kabupaten Padangpariaman dipengaruhi oleh sektor yang sama yaitu sektor Transportasi dan Pergudangan, sektor pertanian dan sektor industri pengolahan di Provinsi Sumatera Barat masing-masing sebesar 638,119.35 juta rupiah, 662,106.22 juta rupiah dan $391,303.44$ juta rupiah. 
Pengaruh komponen bauran industri (Mij)yangbernilaipositifmenunjukkanbahwa laju pertumbuhan Sektor perekonomian di Kabupaten Padangpariaman mengalami peningkatan. Sektor yang mengalami pertumbuhan adalah sektor yang memiliki nilai Mij positif. Sektor sektor Transportasi dan Pergudangan merupakan sektor yang memiliki pertumbuhan tertinggi yaitu sebesar 289,737.18 juta rupiah, diikuti oleh sektor konstruksi sebesar 93,778.67 juta rupiah dan sektor informasi dan komunikasi sebesar 70,822.71 juta rupiah. Sektor perekonomian di Kabupaten Padangpariamanyangmengalami penurunan laju pertumbuhan nilai PDRB paling besar adalah sektor Pertanian, Kehutanan, dan Perikanan dengan nilai sebesar -257,815.85 juta rupiah dan sektor Industri Pengolahan sebesar -82,279.34 juta rupiah
Berdasarkan nilai komponen keunggulan kompetitifnya (Cij), terdapat delapan sektor yang memiliki keunggulan kompetitif yaitu Sektor Pertanian, Kehutanan, dan Perikanan, Sektor Pertambangan dan Penggalian, sektor Industri Pengolahan, sektor Perdagangan Besar dan Eceran; Reparasi Mobil dan Sepeda Motor, Sektor Informasi dan Komunikasi, Sektor Jasa Perusahaan, Sektor Administrasi Pemerintahan, Pertahanan dan Jaminan Sosial Wajib dan sektor Jasa Kesehatan dan Kegiatan Sosial. Nilai Cij yang negatif pada sektor sektor lainnya menunjukkan bahwa sektor ekonomi tersebut mengalami penurunan competitiveness relatif terhadap sektor yang sama pada tingkat provinsi dalam kurun waktu tersebut.

Tabel 7. Perbandingan Struktur Ekonomi Provinsi Sumatera Barat Pariaman dan Kabupaten Padang tahun 2016 (persen)

\begin{tabular}{|c|c|c|c|}
\hline No & Lapangan usaha & Padangpariaman & Sumatera Barat \\
\hline \multicolumn{2}{|r|}{ Primer : } & 26.91 & 27.33 \\
\hline A & Pertanian, Kehutanan, dan Perikanan & 21.20 & 23.10 \\
\hline B & Pertambangan dan Penggalian & 5.71 & 4.23 \\
\hline \multicolumn{2}{|r|}{ Sekunder : } & 21.27 & 19.99 \\
\hline C & Industri Pengolahan & 13.27 & 10.92 \\
\hline D & Pengadaan Listrik dan Gas & 0.03 & 0.11 \\
\hline$E$ & Pengadaan Air, Peng. Sampah, Limbah dan Daur Ulang & 0.05 & 0.10 \\
\hline $\mathrm{F}$ & Konstruksi & 7.92 & 8.86 \\
\hline \multicolumn{2}{|r|}{ Tersier : } & 51.82 & 52.68 \\
\hline G & Perdagangan Besar dan Eceran; Rep. Mobil dan Spd mtr & 9.89 & 15.37 \\
\hline $\mathrm{H}$ & Transportasi dan Pergudangan & 23.26 & 11.81 \\
\hline 1 & Penyediaan Akomodasi dan Makan Minum & 0.80 & 1.07 \\
\hline $\mathrm{J}$ & Informasi dan Komunikasi & 3.93 & 6.67 \\
\hline K & Jasa Keuangan dan Asuransi & 1.59 & 3.05 \\
\hline $\mathrm{L}$ & Real Estate & 1.01 & 1.95 \\
\hline $\mathrm{M}, \mathrm{N}$ & Jasa Perusahaan & 0.09 & 0.44 \\
\hline 0 & Administrasi Pemerintahan, Pertahanan dan Jamsos wjb & 5.00 & 5.60 \\
\hline$P$ & Jasa Pendidikan & 4.44 & 3.71 \\
\hline Q & Jasa Kesehatan dan Kegiatan Sosial & 0.59 & 1.31 \\
\hline$R, S, T, U$ & Jasa lainnya & 1.22 & 1.68 \\
\hline
\end{tabular}

Sumber: BPS Kabupaten Padangpariaman dan Prov. Sumatera Barat 
Klasifikasi sektor perekonomian daerah dapat dilakukan dengan membandingkan antara perekonomian suatu daerah dengan daerah yang berada pada tingkat yang lebih tinggi, hal ini bertujuan untuk mengetahui klasifikasi sektor berdasarkan pada perbandingan laju pertumbuhan dan kontribusi sektor (Paulus 2015). Berdasarkan tabel 7, Jika dilihat dari struktur ekonomi, dapat disimpulkan bahwa sektor yang paling dominan di Kabupaten Padangpariaman dan Provinsi Sumatera Barat pada tahun 2016 adalah sektor tersier dan Sektor primer. Pada sektor Tersier Kabupaten Padangpariaman menyumbang kontribusi ekonominya sebesar 51.82 persen dengan kontribusi terbesar oleh sektor Transportasi dan Pergudangan sebesar 23.26 persen dan sektor Perdagangan Besar dan Eceran, Reparasi Mobil dan Sepeda Motor sebesar 9.89 persen. Sementara di Provinsi Sumatera Barat Sektor Tersier menyumbang 52.68 persen dengan kontribusi sektor Perdagangan Besar dan Eceran, Reparasi Mobil dan Sepeda Motor sebesar 15.37 persen, sektor Transportasi dan Pergudangan sebesar 11.81 persen.

Pada Kabupaten Padangpariaman peranan sektor Primer hanya mencapai 26,91 persen di mana sektor Pertanian, Kehutanan, dan Perikanan memiliki peranan hanya sebesar 21.20 persen. Sementara itu, di Provinsi Sumatera Barat, kontribusi sektor Primer mencapai 27.33 persen yang dimotori sektor Pertanian, Kehutanan, dan Perikanan sebesar 23.10 persen. Dari sektor Sekunder, di Kabupaten Padangpariaman hanya sebesar 21.27 persen lebih besar bila dibandingkan di Provinsi Sumatera Barat yang hanya mencapai 19.99 persen. Sektor Sekunder di Kabupaten Padangpariaman didominasi oleh Sektor Industri Pengolahan dengan kontribusi sebesar 13.70 persen, sedangkan di Provinsi Sumatera Barat sektor sekunder yang didominasi oleh industri pengolahan kontribusinya sebesar 10.92 persen.

Tabel 8 Hasil Analisis Overlay (Typology Klassen, DLQ, dan Shift Share) Sektor Perekonomian di Kabupaten Padangpariaman Tahun 2011-2016

\begin{tabular}{|c|c|c|c|c|c|}
\hline No & Lapangan Usaha & Tipologi Klassen & $L Q+D L Q$ & Shift Share & Keterangan \\
\hline A & Pertanian, Kehutanan, dan Perikanan & - & - & - & Non Unggulan \\
\hline B & Pertambangan dan Penggalian & + & + & - & Non Unggulan \\
\hline $\mathrm{C}$ & Industri Pengolahan & + & + & + & Unggulan \\
\hline $\mathrm{D}$ & Pengadaan Listrik dan Gas & - & - & + & Non Unggulan \\
\hline$E$ & $\begin{array}{l}\text { Pengadaan Air, Pengelolaan } \\
\text { Sampah, Limbah dan Daur Ulang }\end{array}$ & - & - & - & Non Unggulan \\
\hline $\mathrm{F}$ & Konstruksi & - & - & - & Non Unggulan \\
\hline G & $\begin{array}{l}\text { Perdagangan Besar dan Eceran; } \\
\text { Reparasi Mobil dan Sepeda Motor }\end{array}$ & - & - & + & Non Unggulan \\
\hline $\mathrm{H}$ & Transportasi dan Pergudangan & - & - & - & Non Unggulan \\
\hline I & $\begin{array}{l}\text { Penyediaan Akomodasi \& Makan } \\
\text { Minum }\end{array}$ & - & - & - & Non Unggulan \\
\hline $\mathrm{J}$ & Informasi dan Komunikasi & - & - & + & Non Unggulan \\
\hline $\mathrm{K}$ & Jasa Keuangan dan Asuransi & - & - & - & Non Unggulan \\
\hline $\mathrm{L}$ & Real Estate & - & - & - & Non Unggulan \\
\hline $\mathrm{M}, \mathrm{N}$ & Jasa Perusahaan & - & - & + & Non Unggulan \\
\hline $\mathrm{O}$ & $\begin{array}{l}\text { Administrasi Pemerintahan, Pertah- } \\
\text { anan dan Jaminan Sosial Wajib }\end{array}$ & - & - & + & Non Unggulan \\
\hline $\mathrm{P}$ & Jasa Pendidikan & - & - & - & Non Unggulan \\
\hline Q & Jasa Kesehatan dan Kegiatan Sosial & - & - & + & Non Unggulan \\
\hline $\mathrm{R}, \mathrm{S}, \mathrm{T}, \mathrm{U}$ & Jasa lainnya & - & - & - & Non Unggulan \\
\hline
\end{tabular}

Sumber: Data diolah 


\section{Penentuan Sektor Unggulan di Kabupaten Padangpariaman}

Berdasarkan Identifikasi overlay jika ketiga hasil hitungan gabungan yaitu typology klassen, LQ dan DLQ dan shift share menunjukkan nilai positif $(+++)$ maka dikatakan bahwa sektor tersebut merupakan sektor unggulan di Kabupaten Padangpariaman. Hasil Analisis Overlay dapat dilihat pada Tabel 8.

Berdasarkan Tabel 8 yaitu analisis Overlay menunjukkan sektor yang memenuhi kriteria analisis Overlay yaitu memiliki koefisien Positif (+++) dari ketiga alat analisis tersebut adalah sektor pertambangan dan penggalian. Sektor lain yang memiliki peluang menjadi sektor unggulan adalah sektor industri pengolahan yang berdasarkan analisis overlay hanya memiliki koefisien positif Klassen Typologi dan Gabungan LQ Dan DLQ (+ +).

\section{SIMPULAN}

Beberapa simpulan yang dapat ditarik dalam penelitian ini adalah sebagai berikut.

1. Berdasarkan hasil analisis Tipology Klassen, sektor pertambangan dan penggalian dan sektor industri pengolahan berada pada kuadran i yang merupakan sektor prima/andalan (maju dan cepat tumbuh) di daerah;

2. Hasil analisis Location Quotient menunjukkan terdapat empat sektor basis di Kabupaten Padangpariaman yaitu sektor pertambangan dan penggalian, sektor industri pengolahan, sektor transportasi dan pergudangan dan sektor jasa pendidikan;

3. Analisis Dynamic Location Quotient menunjukkan bahwa terdapat sepuluh sektor dengan nilai DLQ $>1$, yang diharapkan pada masa yang akan datang dapat menjadi sektor basis dan unggulan. Terdapat satu sektor yang awalnya memiliki LQ sangat tinggi namun dalam
DLQ berubah menjadi sektor nonbasis yaitu sektor jasa Pendidikan, hal ini tentu harus menjadi perhatian bagi pemda dalam membuat langkah strategis dan penyusunan perencanaan pembangunan daerah terutama prioritas sektor ekonomi unggulan daerah.

4. Berdasarkan hasil analisis gabungan LQ dan DLQ menunjukkan bahwa terdapat delapan sektor yang mengalami reposisi dari nonbasis menjadi sektor basis di masa yang akan datang, yaitu sektor pertanian, kehutanan, dan perikanan, sektor pengadaan listrik dan gas, sektor perdagangan besar dan eceran; reparasi mobil dan sepeda motor, sektor informasi dan komunikasi, sektor jasa keuangan dan asuransi, sektor jasa perusahaan, sektor administrasi pemerintahan, pertahanan dan jaminan sosial wajib dan sektor jasa kesehatan dan kegiatan sosial

5. Dari hasil overlay (penggabungan) ditemukan bahwa sektor industri pengolahan merupakan sektor yang paling unggul/andalan di daerah Kabupaten Padangpariaman.

\section{DAFTAR PUSTAKA}

Abidin, Z. (2015, Desember). Aplikasi Analisis Shift Share Pada Transformasi Sektor Pertanian Dalam Perekonomian Wilayah Di Sulawesi Tenggara. Informatika Pertanian, Vol. 24 (No.2), 165-178.

Arsyad, L. (1999). Pengantar Perencanaan dan Pembangunan Ekonomi Daerah. Yogyakarta: BPFE-UGM

Badan Pusat Statistik Sumatera Barat, 2016. Produk Domestik Regional Bruto Provinsi Sumatera Barat 2010-2016

Badan Pusat Statistik Padangpariaman, 2016. Produk Domestik Regional Bruto Kabupaten Padangpariaman 2010-2016.

Glasson, John, 1977. Pengantar Perencanaan Regional, Terjemahan Paul Sitohang, Lembaga Penerbit FE UI, Jakarta. 
Hajeri, Erlinda Yurisinthae, Eva Dolorosa. (2015). Analisis Penentuan Sektor Unggulan Perekonomian di Kabupaten Kubu Raya. Jurnal Ekonomi Bisnis dan Kewirausahaan, 4(2), 253-269.

Kuncoro, M. (2004). Otonomi dan Pembangunan Daerah: Reformasi, Perencanaan, Strategi dan Peluang. Jakarta: Erlangga.

Ni Made Winda Savitri Dewi, I Nyoman Mahaendra Yasa. (2018, Januari). Analisis Sektor Potensial Dalam Menetapkan Perencanaan Pembangunan di Kabupaten Karangasem. E-Jurnal EP, 7(1), 152-183. Retrieved april 10, 2019

Ni Komang Erawati, I Nyoman Mahaendra Yasa, 2011. Analisis Pola Pertumbuhan Ekonomi dan Sektor Potensial Kabupaten Klungkung. Jurnal Fakultas Ekonomi Universitas Udayana, Bali, https://media. neliti.com/media/publications/44668ID-analisis-pola-pertumbuhan-ekonomidan-sektor-potensial-kabupatenklungkung.pdf

Rosita Wahyuningtyas, Agus Rusgiyono, Yuciana Wilandari. (2013). Analisis Sektor Unggulan Menggunakan Data PDRB (Studi Kasus BPS Kabupaten Kendal Tahun 2006-2010). Jurnal Gaussian, Volume 2 (3), 219-228. Retrieved April 26, 2019, from http://ejournal-s1.undip. ac.id/index.php/gaussian

Sirojuzilam. (2008). Disparitas Ekonomi dan Perencanaan Regional, Ketimpangan Ekonomi Wilayah Barat dan Wilayah Timur Provinsi Sumatera Utara. Medan: Pustaka Bangsa Press.
Sjafrizal. (2014). Perencanaan Pembangunan Daerah Dalam Era Otonomi. Jakarta: Rajawali Press.

Syafrizal. (1997). Pertumbuhan Ekonomi dan Ketimpangan Regional Wilayah Indonesia Bagian Barat. Jakarta: Prisma LP3ES.

Syafrizal. (2008). Ekonomi Regional, Teori dan Aplikasi. Padang: Baduose Media.

Tambunan, T. (2001). Transformasi Ekonomi di Indonesia; Teori dan Penemuan Empiris. Jakarta: Salemba Empat.

Tarigan, R. 2. (2012). Ekonomi Regional: Teori dan Aplikasi. (Vol. Edisi Revisi). Jakarta: PT. Bumi Aksara.

Yolamalinda. (2014). Analisis Potensi Ekonomi Daerah Dalam Pengembangan Komoditi Unggulan Kabupaten Agam. Economica, 3(1),27-41. http://dx.doi.org/10.22202/ economica.2014.v3.i1.234

Yulianita, A. (2010, Desember). Analisis Sektor Ekonomi Ungggulan di Kabupaten Muara Enim. JURNAL EKONOMI PEMBANGUNAN, Volume 8(2), 98-113.

Usya, N. (2006). Analisis Struktur Ekonomi dan Identifikasi Sektor Unggulan di Kabupaten Subang. Skripsi, Fakultas Ekonomi dan Manajemen. IPB. Bogor 